\title{
Age Determination of Martian Low Shield Volcanoes by Crater Size-Frequency Measurements
}

\author{
Felix Jagert, Bochum \& Ernst Hauber, Berlin
}

Keywords: Volcanism, crater, planetary, remote sensing, Mars

\begin{abstract}
Summary: Based on high-resolution images of the current NASA-spacecraft Mars Reconnaissance Orbiter, the technique to determine absolute ages of planetary surfaces by impact crater counts is demonstrated. The results will be useful to interpret geologic processes on the planet's surface, such as the history of volcanic activity. This paper describes the statistical technique for a low shield volcano in the Tharsis region and its adjacent plains with the discussion of the results and problems. Planetary remote sensing data are processed and prepared for the later use in GIS environments and statistical analysis. The crater counts were done independently with two different cameras, which provided comparable results. The derived absolute ages are in good agreement with the results of earlier works.
\end{abstract}

\section{Introduction and Related Work}

It is known for decades that the planet Mars was volcanically active in its geological past. A major goal in planetary geology is to investigate the times of activity and whether the volcanoes are now extinct or dormant. These results will be a key to determine the history of late-stage volcanism of the planet and will help to shed light on the endogenic evolution of Mars.

Much research was done for the big shield volcanoes (e.g., Olympus Mons) in the Tharsis region in the western Martian hemisphere, a huge topographic bulge with widespread vol-
Zusammenfassung: Altersbestimmung von niedrigen Schildvulkanen auf dem Mars anhand von Kratergrößen-Häufigkeitsverteilungen. Auf Grundlage der aktuellen, hochauflösenden Bilddaten der NASA-Raumsonde Mars Reconnaissance Orbiter wird die etablierte Methode der absoluten Altersbestimmung planetarer Oberflächen anhand von Kraterhäufigkeiten demonstriert. Die Ergebnisse dienen der wissenschaftlichen Interpretation geologischer Prozesse auf dem Mars, wie etwa der Untersuchung der vulkanischen Aktivität des Planeten. In diesem Beitrag wird diese statistische Methode beispielhaft für einen Schildvulkan und dessen Umgebung in der Tharsis-Region angewandt, Ergebnisse diskutiert und Probleme angesprochen. Dazu wurden die planetaren Fernerkundungsdaten prozessiert, für die spätere Verarbeitung in Geographischen Informationssystemen vorbereitet und statistisch ausgewertet. Zum Vergleich der Kraterstatistiken wurden die Aufnahmen von zwei verschiedenen Kameras verwendet, die gleichartige Ergebnisse lieferten. Die bestimmten Alter stimmen sehr gut mit den Ergebnissen vorheriger Autoren überein. canic resurfacing. Remote sensing images and topographic data, however, show also several clusters of small, low shield volcanoes in Tharsis.

These Martian low shield volcanoes and associated landforms show morphologic characteristics that are comparable with basaltic volcanic provinces on Earth (PlesCIA 1981, HAuber et al. 2009). Plains volcanism of the eastern Snake River Plain in Idaho (USA) can be considered as possibly the best terrestrial morphological analogue for this type of volcanism. It is defined as being an intermediate style between flood basalts and the Hawaiian shields (GreELEy 1982). The Martian shield 
clusters are overlapping each other and form a spatially extended volcanic unit with hundreds of vents. Single shield edifices have average diameters of several tens of kilometers. Although a widespread eolian dust mantle is masking the spectral signature in large parts of Tharsis, the observable geomorphologic features show that the Martian low shield volcanoes are most likely consisting of basaltic lavas with very low viscosity (HAUBER et al. 2009, HAUBER et al. 2011).

To reconstruct the timeline of volcanic activity of the low shields clusters, HAUBER et al. (2011) recently produced a Tharsis-wide chronology by crater counts and also estimated lava rheologies. Most small volcanoes have ages of $<100$ million years (Ma) and two clusters are older with ages of a few hundred million years up to ages of $0.3-2.9$ billion years (Ga) (Hauber et al. 2011). The results show that plains volcanism was active very recently in the last few percent of Mars' geologic history. An ongoing investigation of the volcanic vents in this area could probably detect latestage eruptions that were even more recent. In conclusion, it cannot be excluded that Mars is volcanologically only dormant, and might be active in the near future.

The geological mapping and investigation of small surfaces on Mars is possible since cameras on planetary space probes are transmitting high-resolution data with resolutions of meters per pixel. In our study the high-resolution data of the Mars Reconnaissance Orbiter (MRO) have been used for geological mapping and the preparation of crater counts to estimate the absolute age of a low shield volcano and the surrounding plains in Noctis Labyrinthus, in the east part of Tharsis. In addition a laser altimetry track, also acquired by the Mars Global Surveyor (MGS), has been used to construct a profile for morphometric analysis.

In the past, crater counts were done using a stereo comparator with analog images. Nowadays, the complete workflow can be performed digitally with Geographic Information Systems (GIS). The aims of this study are to demonstrate the age determination of planetary surfaces by impact crater counts and the integration of planetary remote sensing data into GIS.

\section{Age Determination by Impact Crater Counts}

The age determination of planetary surfaces by impact crater counts is an important and established tool to interpret geologic surfaces and stratigraphic relationships on other planets and moons. Due to the random accumulation of impact craters on a planetary surface over a prolonged period, it is possible to assess its age. An intense modification by erosion, deposition of material or coverage by lava flows is resetting the surface-age to zero and the crater accumulation is starting again (Hartmann \& Neukum 2001).

It is possible to map a geologic unit and to establish relative and absolute ages by crater size-frequency distributions, a technique described in detail by Hartmann \& Neukum (2001) and Ivanov (2001), Neukum \& Wise (1976) and references therein. In the past, lunar crater frequencies could be inverted to absolute ages by comparison with Apollo rock samples that were dated by radiometric crystallization ages. A chronology function could be approximated which is describing a nearly constant cratering rate during the last $3 \mathrm{Ga}$ and an exponentially decreasing rate before 3 Ga (early intense bombardment). The cratering chronology model of the Moon was adjusted for Mars taking into account several

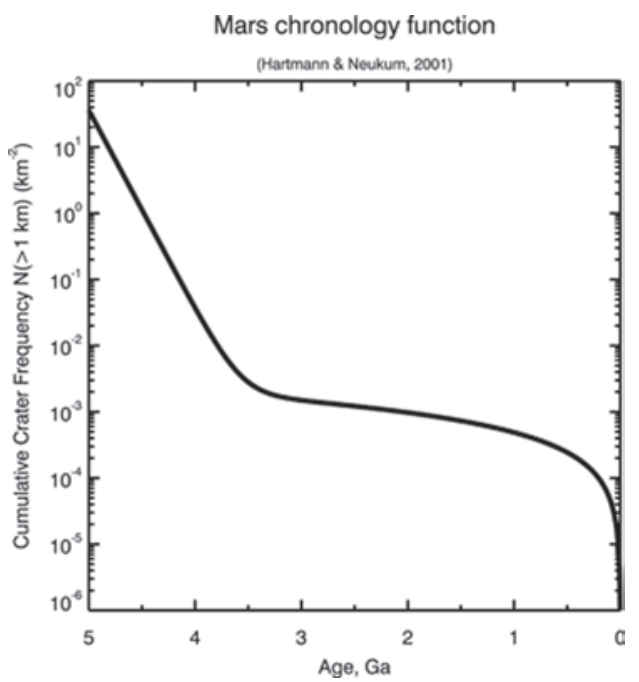

Fig. 1: Mars chronology function by HARTMANN \& NEUKum (2001). 
parameters like different orbital mechanics, crater scaling and impact flux (NEUKUM et al. 2010) (Fig. 1). Important for the adaption of the lunar chronology to the Martian chronology was the estimation of the cratering rate of Mars relative to the Moon (production function). With this function the production-rate of craters of any given diameter on a given surface is assumed to be known (HARTMANN \& Neukum 2001, Ivanov 2001).

These established methods enable to determine relative and absolute ages of a given surface by cumulative crater size-frequency distributions (CSFD). The idea is to plot the crater counts as CSFD normalized to a unit area and to fit the production function to the data points. With a correct fit the chronology function can calculate absolute surface model ages (Michael \& Neukum 2010).
Hartmann \& Neukum (2001) calculated that crater counts provide dates with an uncertainty within a factor of 2 for ages $<3.5 \mathrm{Ga}$ and $\pm 100 \mathrm{Ma}$ for ages $>3.5 \mathrm{Ga}$, caused mainly by flux uncertainties. This implies that all estimated absolute ages can be either too young or too old. The observation of the recent Martian impact-rate by repeated remote sensing images over a seven-year period actually showed that the predicted rate is in close agreement with the current observed impact-rate (HARTMANN 2007, WERNER 2009).

\section{Investigation Area}

As an example to demonstrate the technique of crater size-frequency measurements, we selected a low shield volcano in the north

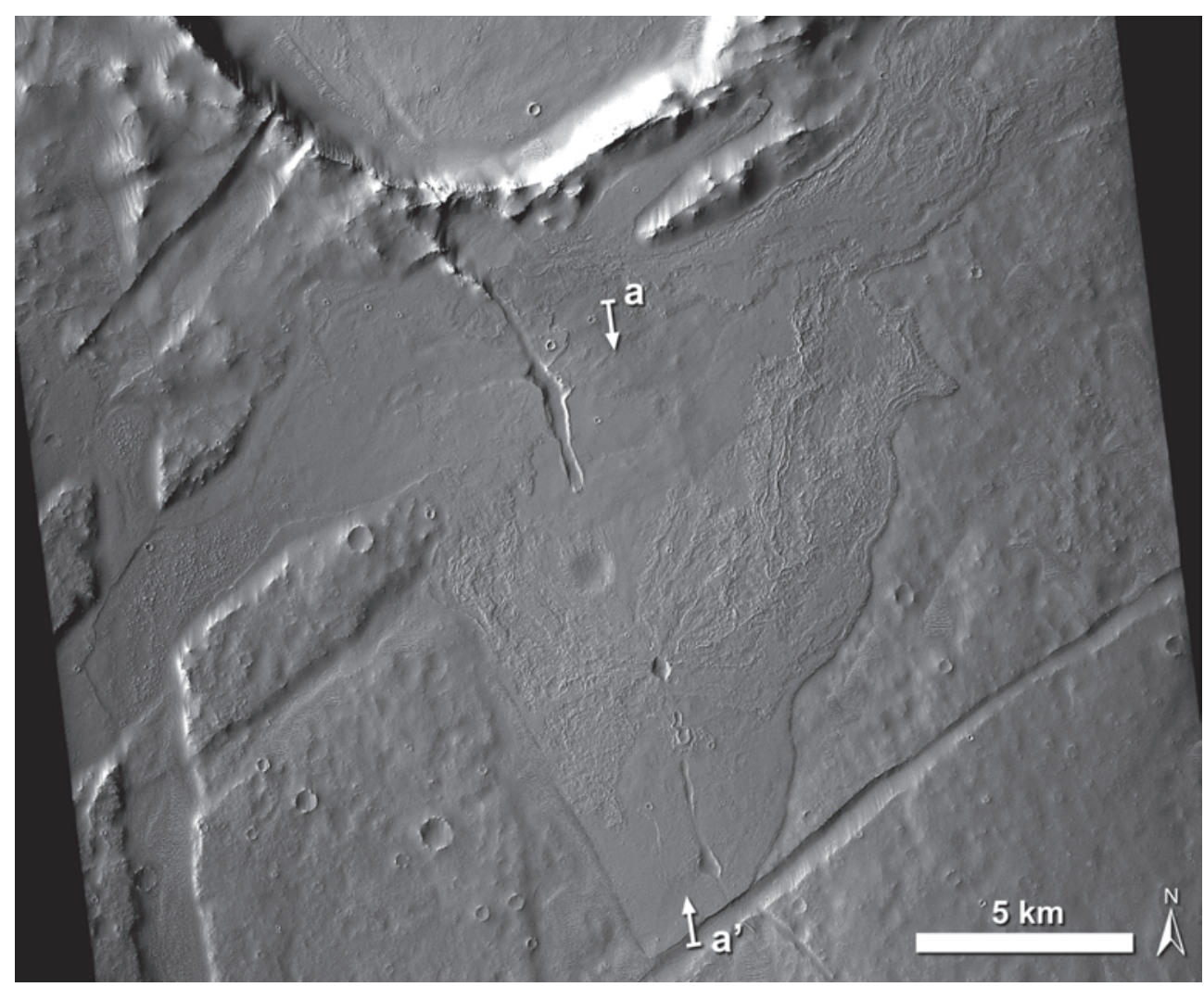

Fig. 2: Low shield volcano in the north of Noctis Labyrinthus, centered at $-3.65^{\circ} \mathrm{N} / 253.27^{\circ} \mathrm{E}$ (CTXimage B02_010226_1765_XI_03S106W; taken in October 2008). The marked profile a - a' is shown in Fig. 3. The shield shows several summit craters and elongated vents and is mainly bordered by faults. The subdued circular depression in the NW of the main summit is not an impact crater but rather a collapse structure induced by tectonics. 


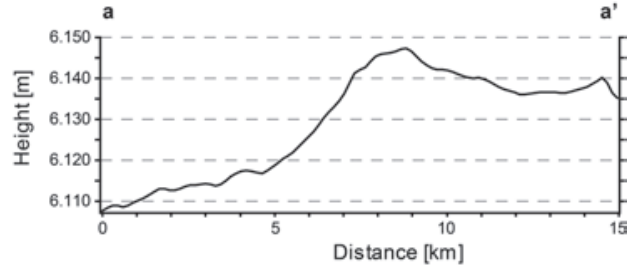

Fig. 3: Topographic MOLA-profile, crossing the low shield volcano from a-a'. The volcano has a height of only a few tens of meters and is sloping to north.

of Noctis Labyrinthus in the eastern part of Tharsis. The study site is a transitional zone between the volcanic plains in Tharsis and a region strongly modified by tectonics (Fig. 2). The fault trends in this area are mainly oriented NNW/SSE, N/S and ENE/WSW. The region shows much more craters than the lava plains and is covered by an eolian dust layer, which is also visible as dunes. This low shield was chosen because it is clearly distinguishable from the surroundings. The eruption took place at several summit craters and elongated vents, which are aligned along a tectonic trend oriented NNW/SSE. The topographic profile (Fig. 3) shows the morphometry of the main summit, which has a height of only a few tens of meters with a base sloping downwards to north. The general slope of the terrain forced the lava to flow northwards, where it drained into grabens in ENE/WSW direction or was stopped by an old crater rim. The observed morphometry and gentle slopes of the volcanic construct emphasize the results of HAUBER et al. (2011) that this type of volcanism is consisting of basaltic lavas with low viscosity.

\section{Data and Methods}

\subsection{Remote Sensing Data}

We used images of the Mars Reconnaissance Orbiter, a planetary space probe which is orbiting Mars since 2006. There are two cameras onboard: The panchromatic images of the Context Camera (CTX) are ideal to cover an entire shield construct with a swath-width of $\sim 30 \mathrm{~km}$ and a spatial resolution of $\sim 5.5 \mathrm{~m} / \mathrm{pix}-$ el. The panchromatic and multispectral images of the High Resolution Science Experiment
(HiRISE) have a swath-width of about $\geq 3 \mathrm{~km}$ at $200 \mathrm{~km}$ altitude with resulting resolutions of about $0.25-0.3 \mathrm{~m} /$ pixel (Malin et al. 2007, McEwen et al. 2007). The satellite acquired simultaneous observations with the two cameras of this site in October 2008, which have been selected for crater counts. These two observations made it possible to date the volcano by independent crater counts at different ranges of spatial resolutions to verify the results of the CSFDs.

In addition, data of the Mars Orbiter Laser Altimeter (MOLA) of the Mars Global Surveyor (MGS) Mission have been used for topographic analysis. This instrument measured topographic elevations of the entire planet with orbital nadir-tracks with an alongtrack shot spacing of $\sim 300 \mathrm{~m}$ (vertical accuracy $\sim 1 \mathrm{~m}$ ) (Sмith et al. 2001). A single track of this dataset was generated directly over the main summit, which was used to draw a profile of the shield construct (Fig. 3).

Planetary remote sensing data are accessible through the Orbital Data Explorer (ODE). The ODE is a web-portal which is distributing the data of several planetary missions from NASA and ESA for Mars, Moon and Mercury at no cost (WANG et al. 2011).

\subsection{Pre-Processing}

The software ArcGIS 9.3/10 from Esri was used for mapping and crater counts. Most planetary data cannot be directly imported into commercial GIS environments. Therefore, several processing steps are essential.

The planetary images were pre-processed with the Integrated Software for Imagers and Spectrometers (ISIS 3) for LINUX, a software developed by the USGS (U.S. Geological Survey) and NASA, with multi-mission capabilities for handling data acquired by several planetary space probes. The camera models, spacecraft and planetary ephemerides and the definition of planetary bodies (in our case: Mars) is completely included in this software package (ANDERSON et al. 2004, EliASON 1997, GADDIS et al. 1997).

With ISIS, the CTX data have been radiometrically calibrated (including the removal of systematic noise) and geometrically recti- 
fied from raw-instrument data to a map-projected image. To minimize distortion, a sinusoidal-projection was used with the central meridian crossing the center of the image.

To import the CTX data into ArcGIS, the images were exported to PNG files with world files for georegistering. In ArcGIS the datum of Mars 2000 defined by the International Astronomical Union (IAU) was added (semimajor axis: $3396.19 \mathrm{~km}$, semiminor axis: $3376.20 \mathrm{~km}$ ), which is compatible to the datum used in ISIS.

The HiRISE data are accessible via ODE already completely radiometrically corrected and map-projected in the georegistered JPEG2000 file format. They are delivered in an equirectangular-projection and can be reprojected to avoid distortion. In our case the location is centered near the equator, a low- distortion area of this cartographic projection without the need of reprojection. These georegistered JPEG2000 images are supported by ArcGIS and can be added instantly.

The topographic MOLA data are accessible through a query mask from the ODE. The single point-measurements can be downloaded in common file formats, e.g. as ASCII files or 3D-shapefiles for the use in ArcMap or ArcScene (ArcGIS). A resulting profile is shown in Fig. 3.

\subsection{Mapping and Crater Counts}

After the steps in section 4.2, the planetary remote sensing images can be used for further work in ArcGIS. The geological mappings and crater counts were done with the ArcGIS-
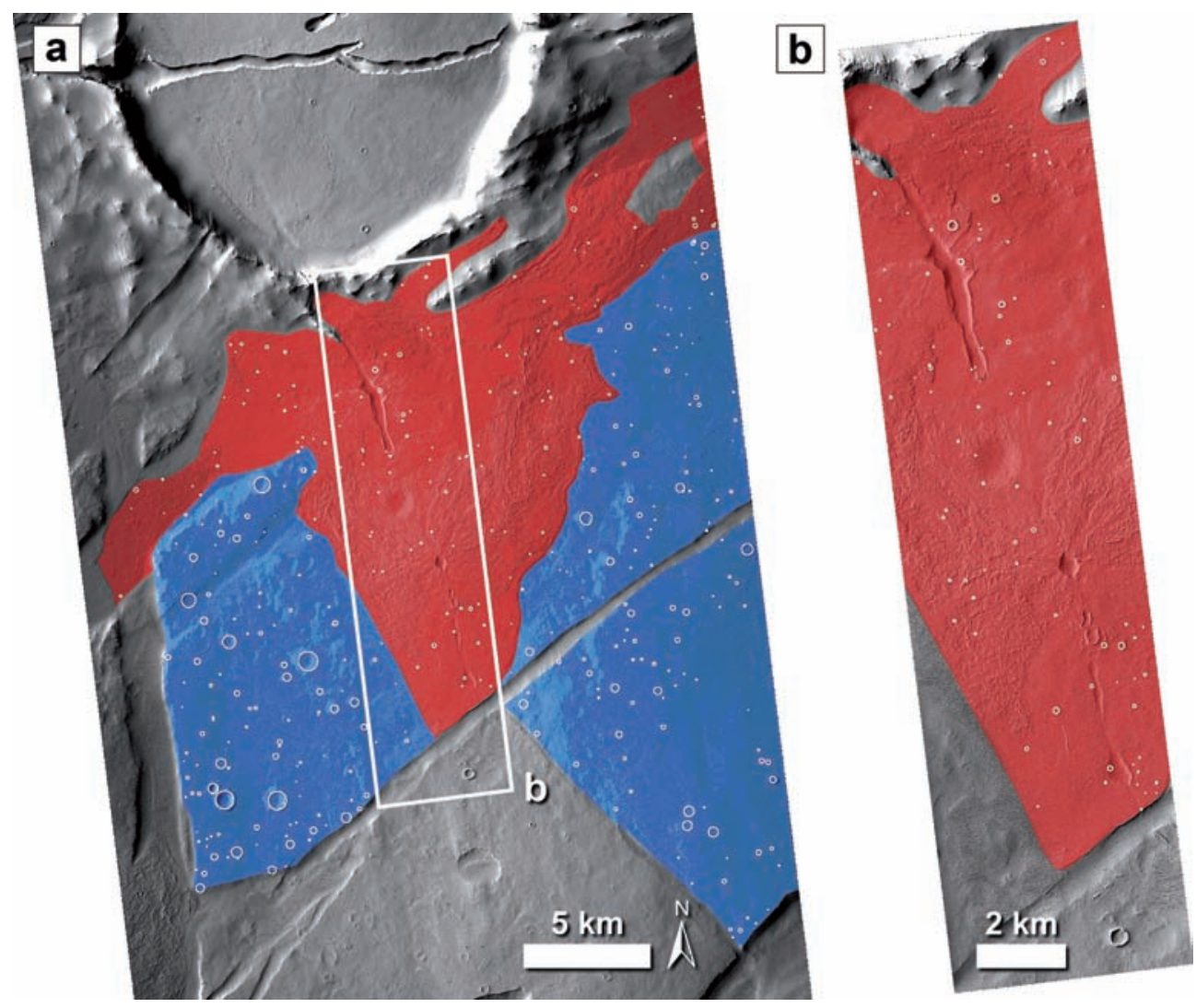

Fig. 4: Mapped stratigraphic units and counted craters (circles) superimposed onto the image strips. a) CTX image with volcano (red) and the adjacent plains (blue). The surrounding plains can probably reflect the buried, older age under the volcano. b) HiRISE image with the mapped volcano (red). This subset represents a statistical sample of the volcanic unit. 

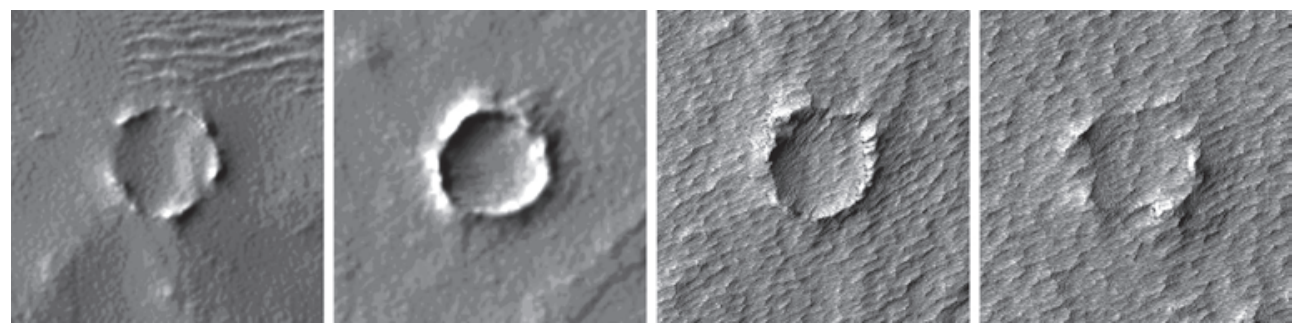

Fig. 5: Examples of impact craters in the counting areas. From left to right: Crater with diameter of $269 \mathrm{~m}$ (CTX), crater with diameter of $191 \mathrm{~m}$ (CTX), crater with diameter of $105 \mathrm{~m}$ (HiRISE), heavily degraded crater with diameter of $\sim 87 \mathrm{~m}$ (HiRISE).

extension CraterTools developed at the Freie Universität Berlin (FUB) (KNEISSL et al. 2011). With this tool it is possible to map the geological unit and to measure the crater-diameters (with a circle) inside the counting area. After this step it is possible to export the results for further analysis. A newer version of this tool is calculating the crater diameter internally without map distortion, independent of the projection used in ArcGIS.

The dating of a planetary surface makes only sense for homogeneous geological or geomorphological units. Different units should be mapped separately. Otherwise the crater populations of two different stratigraphic ages are merged and the CSFD would show a mixed age. Surfaces with steep slopes at scarps are not usable for crater counts because the impact craters are distorted or eroded by mass wasting processes. There is no need to map the complete geological unit. It is also sufficient to map and count an area which is representing a statistical sample of the unit (e.g., HiRISE image in Fig. 4).

Areas with secondary crater clusters should be excluded from the crater count because these types of craters are not included in the Martian crater production function (section 2). Secondary craters are impact craters which are generated by the debris (ejecta) of a large impact. Not every circular feature is an impact crater. Normal impact craters display nearly perfect circular shapes with a crater rim (Fig. 5). Inside of these craters are depressions, sometimes filled with sediments. Volcanic vents, calderas or other collapse structures can be mistaken for impact craters. The local context will help in most instances. When a pit crater is not circularly shaped, without a rim and with lava flowing radial outwards, it is most likely not an impact crater but rather a volcanic vent.

For complete statistics we counted every impact crater (without building classes) with its centre in the counting area. A pre-selection of craters can generate a subjective result.

Two surfaces are dated at the investigation site (Fig. 4). The geological unit of interest is the low shield volcano in the CTX and HiRISE images. In addition, it is of interest to estimate the age of the surrounding plains, which is most likely the age of the surface buried under the volcano. Therefore, homogeneous surfaces adjacent to the volcano, bounded by tectonic faults, are mapped as well. In the SW, the plains are probably contaminated by secondary craters, hence they are not used for dating.

For the volcanic unit in the CTX image we mapped 133 craters with diameters ranging from $21-191 \mathrm{~m}$. The surrounding plains contain 249 craters (diameters: $22-743 \mathrm{~m}$ ) and are probably showing a weak contamination by some huge secondary craters in the western part. The HiRISE observation shows smaller craters due to the increased spatial resolution. The HiRISE image of the volcano contains 93 craters (diameters: 14-193 m).

\subsection{Crater Size-Frequency Distributions}

After the mapping of geologic units and crater counts, the recorded diameters of the craters and the size of the counting area can be imported into the software Craterstats developed at FUB. With this software it is possible to plot the CSFD of the crater counts and to fit it to the production function with a least squares 
method. The crater count results are plotted as reverse-cumulative histogram with log $\mathrm{N}_{\text {cum }}$ vs. $\log$ D. For this work we used the established Martian chronology model of HARTmann \& Neukum (2001) and the Martian production function of Ivanov (2001). The dating by CSFDs is discussed in detail by Michael \& Neukum (2010) and references therein.

For the volcanic surface a minimum diameter of $>60 \mathrm{~m}$ was used for best fitting (adjacent plains: $>250 \mathrm{~m}$ ). $\mathrm{N}_{\text {cum }}$ shows a characteristic fall-off at smaller craters (Fig. 6). A technical reason for this trend is that it becomes more difficult to count small craters at the resolution limit. With complex textures it is likely that some craters are lost. A second reason (especially for the plains adjacent to the volcano) is that the population of smaller crater diameters below $60 \mathrm{~m}$ is disturbed, probably caused by continuous erosion and dust deposition. There are some outliers with diameters in the range of $450-700 \mathrm{~m}$. These potentially secondary craters have been excluded from the fit.

\section{Crater count with CTX}

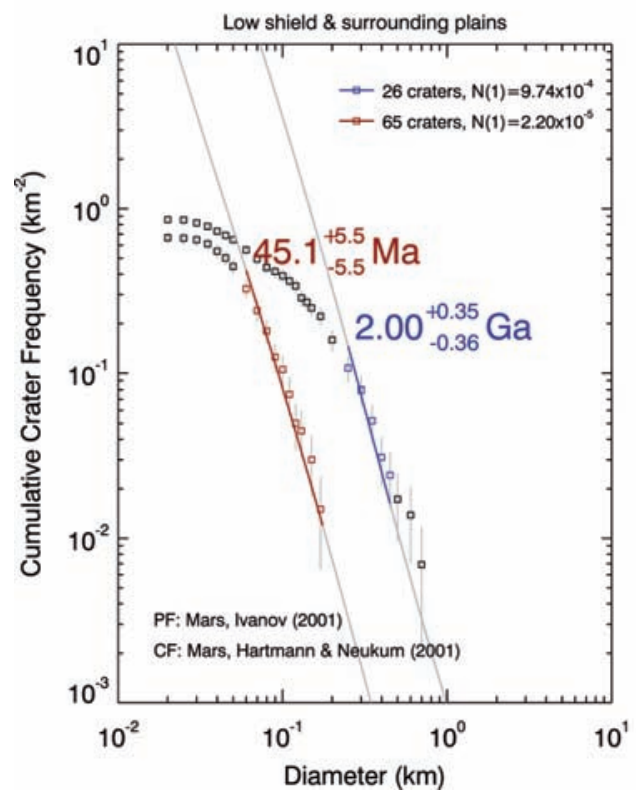

\section{Results and Discussion}

The results of the dating are shown in Fig. 6. The ages show the last time when the geologic activity ended. The last activity of the low shield volcano was $45.1 \mathrm{Ma}$ (CTX) or $42.4 \mathrm{Ma}$ (HiRISE) before today. Therefore, the crater count of the volcano based on the CTX image is verified by the counts on the HiRISE image, which has a completely different resolution and is mapped independently. The estimated ages are very comparable with only a small difference and with overlapping error bars, although the HiRISE observation is only a subset of the unit. The uniform distribution of craters and the lack of huge craters are indicating a short emplacement time without long periods of inactivity.

The adjacent plains around the volcano show an age of $2 \mathrm{Ga}$ with a small "bump" at large craters, which is steepening the plot and has been excluded. These craters have similar sizes and are located only in the western

Crater count with HiRISE

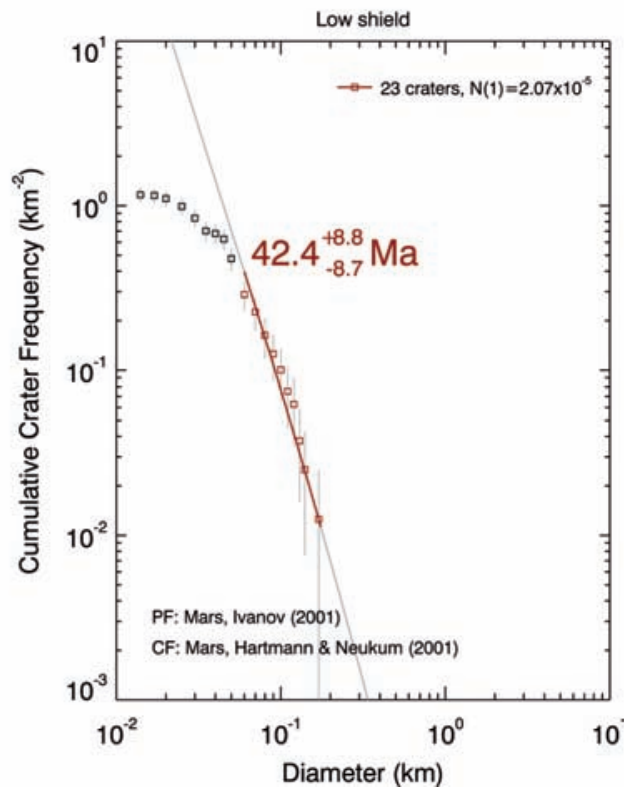

Fig. 6: Cumulative crater frequency plots with the fitted production function. The crater list is binned using pseudo-log bins. Numbers of craters used for the best fit are shown on top of the plots. We use the production function (PF) by Ivanov (2001) and the chronology function (CF) by HaRTMANN \& NEUKum (2001). Left: CTX data plot for the volcanic surface (red), fitted to crater diameters $>60 \mathrm{~m}$, model age: $45.1 \mathrm{Ma}$. The second plot shows the surrounding plains (blue), fitted to crater diameters >250 m, model age: $2 \mathrm{Ga}$. Right: HiRISE data plot for the volcanic surface (subset), fitted to crater diameters $>60 \mathrm{~m}$, model age: $42.4 \mathrm{Ma}$. 
part of the counting area, hence they are expected to be a few secondaries disturbing the natural crater population. However, it is only a negligible amount of secondary craters without clusters. This type of craters is discussed at length in Hartmann (2007) and Michael \& Neukum (2010).

It is very likely that the plains buried under the volcano would show the same age. This means that the plains were formed $\sim 2$ Ga before today. After an unknown time period with continuous erosion, dust deposition (which extinguished smaller craters) and tectonic modification the shield volcano grew possibly very quickly $\sim 45.1 \mathrm{Ma}$ before today. The results indicate that this eruption was active very recently in the Martian geologic history and are in good agreement with HAUBER et al. (2011).

\section{Conclusion}

The age determination by crater size-frequency distributions is an established tool in planetary science to reconstruct the chronology of planetary surfaces. In this study we demonstrated a consistent relationship of the observable geologic stratigraphy and the derived ages by crater counts. This technique can produce reliable results for most surfaces. Exceptions are areas with continuous modification or intense contamination by secondary craters, which would be observable in the resulting CSFDs.

The NASA/USGS-software ISIS was used for the photogrammetric pre-processing of the planetary remote sensing data. After consideration of some aspects (e.g. spatial errors, projection issues, body definitions) the data are usable in GIS environments for mapping or determination of statistical information.

The high-resolution images of the two cameras of the Mars Reconnaissance Orbiter are ideally suited for the preparation of crater counts on small areas. This was not possible with mid- or low-resolution data for several decades in the past. The data of MRO made it attractive to re-investigate numerous small surfaces on Mars. It has been shown that with increasing spatial resolution more small craters can be detected, with a certain lower limit due to the effects of erosion, complex textures or burial by dust deposition.

\section{Acknowledgements}

We thank Thomas Kneissl and Gregory MiCHAEL (Freie Universität Berlin) for making available their software tools CraterTools and Craterstats. In addition, we thank Petr Brož (Academy of Sciences of the Czech Republic) and Piotr JodŁowski (Freie Universität Berlin) for their support of this study.

\section{References}

Anderson, J.A., Sides, S.C., Soltesz, D.L., SucharSKI, T.L. \& BECKER, K.J., 2004: Modernization of the Integrated Software for Imagers and Spectrometers. - Lunar and Planetary Science XXXV (Abstract 2039), Lunar and Planetary Science Institute, Houston.

Eliason, E.M., 1997: Production of Digital Image Models Using the ISIS System. - Lunar and Planetary Science XXVIII: 331-332, Lunar and Planetary Science Institute, Houston.

Gaddis, L.R., Anderson, J., Becker, K., Becker, T., Cook, D., Edwards, K., Eliason, E., Hare, T., Kieffer, H., Lee, E.M., Mathews, J., Soderblom, L, Sucharski, T. \& Torson, J., 1997: An overview of the Integrated Software for Imaging Spectrometers (ISIS). - Lunar and Planetary Science XXVIII: 387-388, Lunar and Planetary Science Institute, Houston.

Greeley, R., 1982: The Snake River Plain, Idaho Representative of a new category of volcanism. - Journal of Geophysical Research 87 (NO.B4): 2705-2712, doi:10.1029/JB087iB04p02705.

Hartmann, W.K. \& Neukum, G., 2001: Cratering Chronology and the Evolution of Mars. - Space Science Reviews 96: 165-194, doi:10.1023/A:1011945222010.

Hartmann, W.K., 2007: Martian cratering 9: Toward resolution of the controversy about small craters. - Icarus 189: 274-278, doi:10.1016/j.icarus.2007.02.011.

Hauber, E., Bleacher, J., Gwinner, K., Williams, D. \& Greeley, R., 2009: The topography and morphology of low shields and associated landforms of plains volcanism in the Tharsis region of Mars. - Journal of Volcanology and Geothermal Research 185: 69-95, doi:10.1016/j.jvolgeores.2009.04.015.

Hauber, E., Broz, P., Jagert, F., Jodlowski, P. \& Platz, T., 2011: Very recent and wide-spread basaltic volcanism on Mars. - Geophysical Research Letters 38: L10201, doi:10.1029/2011GL047310.

Ivanov, B.A., 2001: Mars/Moon Cratering Rate Ratio Estimates. - Space Science Reviews 96: 87104, doi:10.1023/A:1011941121102. 
Kneissl, T., van Gasselt, S. \& Neukum, G., 2011: Map-projection-independent crater size-frequency determination in GIS environments New software tool for ArcGIS. - Planetary and Space Science 59: 1243-1254, doi:10.1016/j. pss.2010.03.015.

Malin, M.C., Bell, J.F., Cantor, B.A., Caplinger, M.A., Calvin, W.M., Clancy, R.T., Edgett, K.S., Edwards, L., Haberle, R.M., James, P.B., Lee, S.W., Ravine, M.A., Thomas, P.C. \& WolfF, M.J., 2007: Context Camera Investigation on board the Mars Reconnaissance Orbiter. - Journal of Geophysical Research 112: E05S04, doi:10.1029/2006JE002808.

McEwen, A.S., Eliason, E.M., Bergstrom, J.W., Bridges, N.T., Hansen, C.J., Delamere, W.A., Grant, J.A., Gulick, V.C., Herkenhoff, K.E., Keszthelyi, L., Kirk, R.L., Mellon, M.T., Squyres, S.W., Thomas, N. \& Weitz, C.M., 2007: Mars Reconnaissance Orbiter's High Resolution Imaging Science Experiment (HiRISE). - Journal of Geophysical Research 112: E05S02, doi:10.1029/2005JE002605.

Michael, G.G. \& Neukum, G., 2010: Planetary surface dating from crater size-frequency distribution measurements: Partial resurfacing events and statistical age uncertainty. - Earth and Planetary Science Letters 294: 223-229, doi:10.1016/j. eps1.2009.12.041.

Neukum, G. \& Wise, D.U., 1976: Mars - A standard crater curve and possible new time scale. - Science 194: 1381-1387, doi:10.1126/science.194.4272.1381.

Neukum, G., Basilevsky, A.T., Kneissl, T., Chapman, M.G., van Gasselt, S., Michael, G., JaUmann, R., Hoffmann, H. \& Lanz, J.K., 2010: The geologic evolution of Mars: Episodicity of resurfacing events and ages from cratering analysis of image data and correlation with radiometric ages of Martian meteorites. - Earth and Planetary Science Letters 294: 204-222, doi:10.1016/j. eps1.2009.09.006.
Plescia, J.B., 1981: The Tempe volcanic province of Mars and comparisons with the Snake River Plains of Idaho. - Icarus 45: 586-601, doi:10.1016/0019-1035(81)90024-5.

Smith, D.E., Zuber, M.T., Frey, H.V., Garvin, J.B., Head, J.W., Muhleman, D.O., Pettengill, G.H., Phillips, R.J., Solomon, S.C., Zwally, H.J., Banerdt, W.B., Duxbury, T.C., Golombek, M.P., Lemoine, F.G., Neumann, G.A., Rowlands, D.D., Aharonson, O., Ford, P.G., Ivanov, A.B., Johnson, C.L., McGovern, P.J., Abshire, J.B., Afzal, R.S. \& Sun, X., 2001: Mars Orbiter Laser Altimeter: Experiment summary after the first year of global mapping of Mars. - Journal of Geophysical Research 106: NO.E10, 23,689-23,722, doi:10.1029/2000JE001364.

Wang, J., Bennett, K.J., Scholes, D.M., Slavney, S., Guinness, E.A. \& Arvidson, R.E., 2011: Searchable Observation Data in PDS's Orbital Data Explorer. - Lunar and Planetary Science 42, Abstract 1896, Lunar and Planetary Science Institute, Houston.

Werner, S.C., 2009: The global martian volcanic evolutionary history. - Icarus 201: 44-68, doi:10.1016/j.icarus.2008.12.019.

Addresses of the Authors:

M.Sc. Geogr. Felix Jagert, Geographisches Institut, Ruhr-Universität Bochum, Universitätsstr. 150, 44780 Bochum, Germany, Tel.: +49-234-9507096, e-mail: felix.jagert@rub.de

Dipl.-Geol. ERnst Hauber, Institut für Planetenforschung, Deutsches Zentrum für Luft- u. Raumfahrt e.V. (DLR), Rutherfordstr. 2, 12489 Berlin, Germany, Tel.: +49-30-67055-325, e-mail: ernst. hauber@dlr.de

Manuskript eingereicht: Dezember 2011

Angenommen: Januar 2012 
